Document downloaded from:

http://hdl.handle.net/10251/138474

This paper must be cited as:

Ortiz Sánchez, MC.; Blanes Campos, C.; Mellado, M. (04-2). An ultra-low pressure pneumatic jamming impact device to non-destructively assess cherimoya firmness.

Biosystems Engineering. 180:161-167. https://doi.org/10.1016/j.biosystemseng.2019.02.003

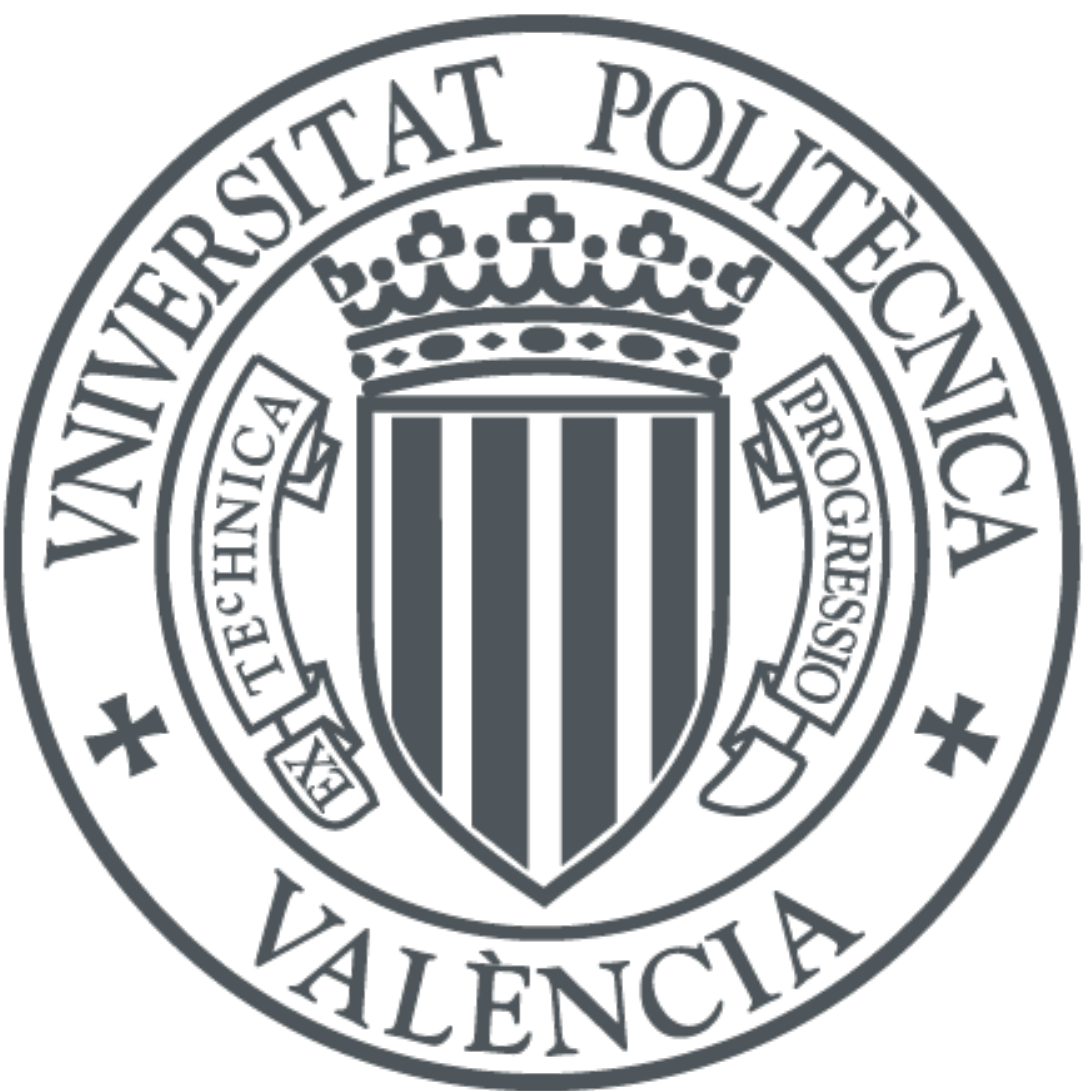

The final publication is available at

https://doi.org/10.1016/j.biosystemseng.2019.02.003

Copyright Elsevier

Additional Information 


\title{
1 An ultra-low pressure pneumatic jamming impact device to non- 2 destructively assess cherimoya firmness
}

3 Coral Ortiz ${ }^{1 *}$, Carlos Blanes ${ }^{2}$ and Martín Mellado ${ }^{2}$

41 Rural and Agri-food Engineering Department, Universitat Politècnica de València, Valencia 46022, Spain; cortiz@dmta.upv.es

62 Instituto Universitario de Automática e Informática Industrial, Universitat Politècnica de València, Valencia 46022, Spain; carblac1@ai2.upv.es; martin@ai2.upv.es

8 * Correspondence: cortiz@dmta.upv.es; Tel.: +34-616-001-xxxx841

Received: date; Accepted: date; Published: date

\begin{abstract}
The quality of cherimoya fruit is reduced by the rapid deterioration of firmness during ripening. Different methods have been developed for the measurement of firmness. The objective of this study was to use a developed impact prototype for the non-destructive assessment and prediction of cherimoya fruit firmness. The prototype has an ultra-low pressure pneumatic jamming rod used to copy the irregular fruit shape. A sample of 200 cherimoyas from Málaga (Spain) 'Fino de Jete' were tested during 4 days. Every day all the fruits were non-destructively tested and a set of 15 were destructively tested. On the fourth day all the remaining fruits were also destructively tested. The prototype was capable of copying the irregularities of the fruit and non-destructively assessing the decrease in cherimoya firmness during ripening without causing damage. A high correlation was found between destructive firmness and non-destructive variables from the prototype. A PLS model was developed to relate destructive firmness from day 4 to non-destructive variables and diameter from day 3 , with a $\mathrm{R}^{2}$ of 75.6 and a RMSECV of 0.9885 . A calibration set confirmed the prediction with a $\mathrm{R}^{2}$ of 80.2 and a RMSEP of 0.0561 . Firmness decay could be non-destructively predicted 24 hours in advance using the variables extracted from the prototype device signal.
\end{abstract}

Keywords: fruit quality; prediction; prototype; deceleration signal; non-damaging.

\section{Introduction}

Cherimoya (Annona cherimola) production for fresh-market consumption is reduced by the rapid deterioration of the fruit during postharvest handling (Alique \& Zamorano, 2000). The fruit ripens quickly, the pulp softens and the peel darkens, being difficult to handle without producing damage (Franco-Mora et al., 2015). One of the deterioration characteristics is softening of the fruit. The measurement of fruit firmness is a suitable method to monitor fruit softening during postharvest handling (Valero, Crisosto, Slaughter, 2007).

Advanced sensing technologies have been developed to non-destructively assess the quality of fresh fruits and vegetables such as: computer vision (Opara \& Pathare, 2014), spectroscopy (Wang, Peng, Xie, Bao, He, 2015), X-rays, hyperspectral techniques (Lorente et al., 2012), magnetic resonance techniques, mechanical contact (Chen \& Opara, 2013), chemical sensing, wireless sensor networks and radiofrequency identification sensors (Ruiz-Altisent et al., 2010; Arendse, Fawole, Magwaza, Opara, 2018). However, most of these techniques are not extensively used in commercial postharvest handling due to their high cost, technical limitations, grower resistance and supply chain restrictions. However, the successful application of NIR spectroscopy to assess fruit quality has been limited to fruits with homogeneous pulp and thin rind (De Oliveira, Bureau, Peira-Netto, 2014). 
Different mechanical non-destructive techniques have been developed in order to assess fruit firmness instead of using the traditional destructive test. Fruit response to force (the mechanical thumb method, the Sinclair firmness tester and the laser air-puff), impact force response (the instrumented hammer impact device and load cells) or other devices based on impact forces, rebound technique, acoustic responses to vibrations and impacts, have been used to assess fruit firmness without damaging the fruit (GarcíaRamos, Valero, Hommer, Ortiz-Cañavate, Ruiz-Altisent, 2005; Khalifa, Komarizadeh, Tousi, 2011). However, most of them are used in the laboratory, and new methods which increase accuracy and velocity and decrease cost are still required.

Cherimoya is a very irregular and delicate fruit, for which measuring firmness using impact methods is very difficult. Jamming systems consisting of a mass of granular material encased in an elastic membrane have been used in robotic grippers for gripping objects with complex geometries (Amend, Brown, Rodenberg, Jaeger, Lipson, 2012). A jamming system has been used for copying eggplant and mango fruit shape during the pick \& place process (Blanes, Ortiz, Mellado, Beltrán, 2015; Cortés et al., 2017). One of the fingers adapts and copies the product shape when the jamming of its internal granular material changes from soft to hard.

The objective of the present research study was to non-destructively assess cherimoya firmness using an impact device prototype with an ultra-low pressure pneumatic jamming rod.

\section{Materials and Methods}

\subsection{Vegetal Material}

A sample of 200 cherimoyas from Málaga (Spain) of the 'Fino de Jete' variety were selected in a very unripe stage $(0.1845 \mathrm{~kg}$ mass $(\mathrm{SD}=0.097), 0.0649 \mathrm{~m}$ diameter $(\mathrm{SD}=0.0026), 71.4 \mathrm{~N}$ destructive firmness $(\mathrm{SD}=11.84)$ and $15.3^{\circ} \mathrm{Brix}(\mathrm{SD}=0.81)$ soluble solid content with a refractometer. Fruits were previously stored at $8^{\circ} \mathrm{C}$ and during the experiment days at room conditions $\left(22.63^{\circ} \mathrm{C}(\mathrm{SD}=1.77)\right.$ and 56 $\%$ relative humidity $(\mathrm{SD}=9.06)$ ).

\section{2. $\quad$ Method}

All the fruits were non-destructively tested every day for $4 \mathrm{~d}$ and a set of 15 randomly selected cherimoyas destructively tested (destructive firmness and soluble solid content). After being measured by the non-destructive prototype, the 15 selected fruits were destructively measured by a penetration test (5 mm deformation, $10 \mathrm{~mm}$ rod diameter and $0.001 \mathrm{~m} \mathrm{~s}^{-1}$ speed) using a universal test machine (Ibertest, Madrid, Spain) [15]. Three destructive firmness measurements were done per fruit, one at the same point and two more at the equatorial surface. Soluble solids content (SSC, ${ }^{\circ}$ Brix) was determined with a digital refractometer (PR-101 ATAGO, Norfolk, VA). Mass and diameter were also measured and the equatorial diameter determined using a digital calliper (0.001 mm accuracy).

The ready-to-eat stage was considered when the flesh was uniformly creamy and glossy white, with a custard-like consistency, with no more than $10 \%$ browning of the skin area (Alique \& Zamorano, 2000).

On the fourth day all the remaining fruits (155 cherimoyas) were destructively tested by penetration test after the non-destructive firmness measurement. Then, the destructive firmness (obtained by the 
penetration test on day 4) was use as the reference firmness value to be compared to the non-destructive variables obtained from the prototype on day 4.

Besides, in order to predict firmness using the non-destructive variables, the non-destructive variables (obtained from the prototype) from day 3 were used to predict destructive firmness (obtained by the penetration test).

\subsection{Prototype calibration}

At every measuring session the prototype was calibrated with a rubber cylinder with a steel centre (63 mm length, $52 \mathrm{~mm}$ diameter, $7.8 \mathrm{~mm}$ width and $62.2 \mathrm{~N}$ penetration resistance (5 mm deformation, $10 \mathrm{~mm}$ rod diameter and $0.001 \mathrm{~m} \mathrm{~s}^{-1}$ speed)).

\subsection{Prototype device and signal processing}

The non-destructive firmness measurements were provided by the analysis of the impacts of a pad, moved by an ultra-low friction pneumatic cylinder (SMC MQQTB16-50D), against every cherimoya, Figure 1.

2 The pad (A) was located at the pneumatic cylinder end of rod (A) and the pad (B) was located at the cradle. Both pads had a vacuum jamming system capable of adapting to the irregularities of fruit shape. A 4 mono-axial accelerometer (ADXL278, Analog Devices, USA; measurement range of $\pm 50 \mathrm{~g}$ ) was attached 5 to the pad (A). Impacts were sampled with a USB data acquisition (DAQ) 6201 NI (National Instruments, 96 USA).

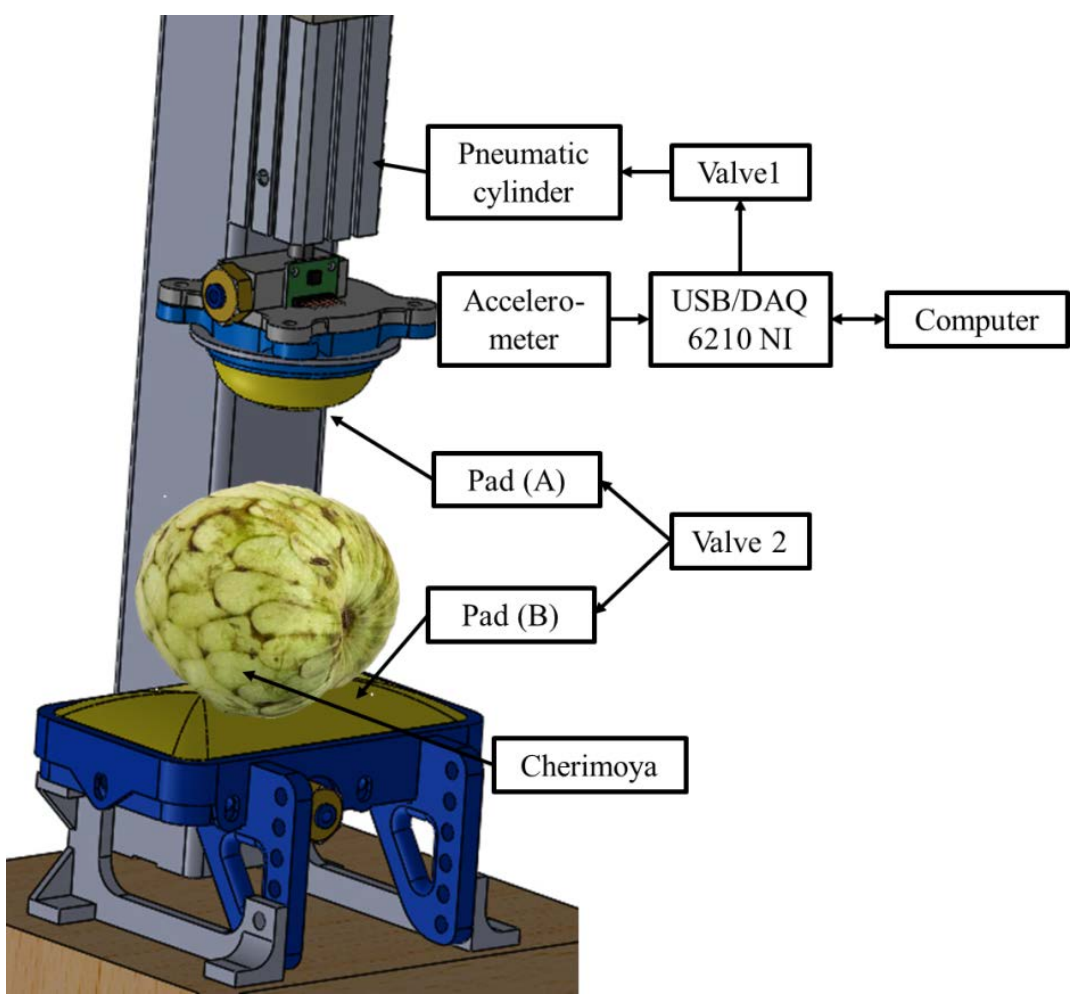

Figure 1. Prototype device used for the assessment of cherimoya firmness. (A) Pneumatic cylinder end of rod, (B) rubber cylinder for calibration, (C) cradle. 
Two programs were used during the process. The first program, LabVIEW11.0 (National Instruments, USA), controlled the pads and the pneumatic cylinder. Valve 1 (SY3120, SMC, Japan) was activated during 0.5 seconds. Two adjustable flowmeter control valves (SMC Ref. AS2201F-01-04S) were used to adjust the speed of the pneumatic cylinder. Pad (A), in soft state, went down and impacted against cherimoya. Valve 2 (SY3120, SMC, Japan) was activated during $0.5 \mathrm{~s}$ and pads (A) and (B) changed from soft to hard state. The air inside pads (A) and (B) was extracted by means of a vacuum generator (Coval Ref GVP20N14), and inside, its particles collapsed. This process was called jamming transition. The pads adapted to the cherimoya shape and kept hard while vacuum process continued. Valve 1 was deactivated during $0.3 \mathrm{~s}$ and pad (A) was raised. Valve 1 was activated during $0.5 \mathrm{~s}$ and, at the same time, a trigger signal was sent to the DAQ. Pad (A) dropped and impacted against cherimoya. Deceleration data were sampled during $0.27 \mathrm{~s}$ at $30 \mathrm{kHz}$ while a computer recorded the signal. The whole process is illustrated in Fig. 2.

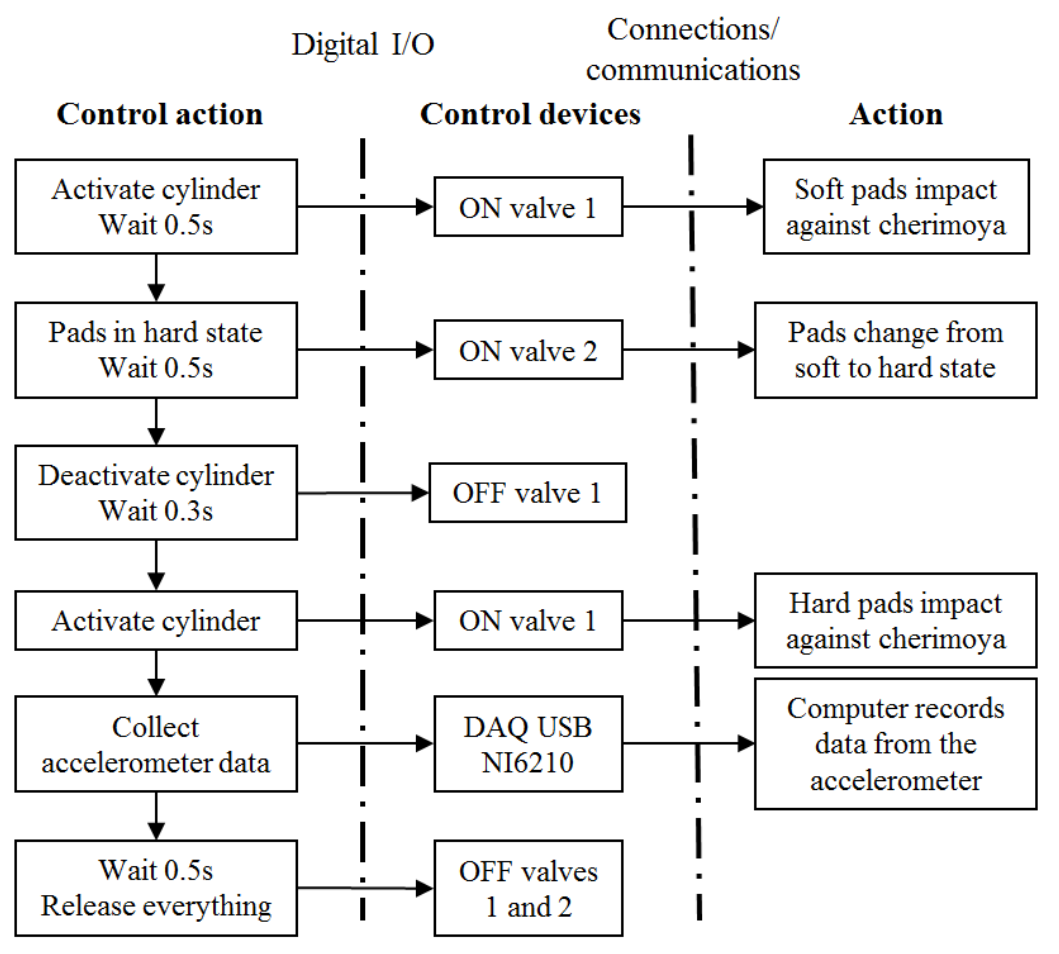

Figure2. Diagram of the control action, devices involved and actions until collecting accelerometer.

The second program, LabVIEW11.0 (National Instruments, USA), processed deceleration data. Firstly, data were low-pass filtered at $1500 \mathrm{~Hz}$. Figure 3 (a) shows the deceleration when the same cherimoya was analysed with this device in different days. Figure 3 (b) shows the signal when pad (A) impacted against cherimoya. This part of the signal was used for extracting three variables. First variable (VE) processed the signal with a Fast Fourier Transform methodology, using the option "measurement magnitude root main square” with Hanning window, to obtain the frequency distribution energy. Variable (VE) was the area of spectral energy of this curve. Second variable (SLP) was average of slope of the deceleration during the first contact of deceleration curve. Third variable (MAX) was the maximum value achieved for this deceleration curve. Detailed process of this methodology is explained in (Blanes et al. 2016). 

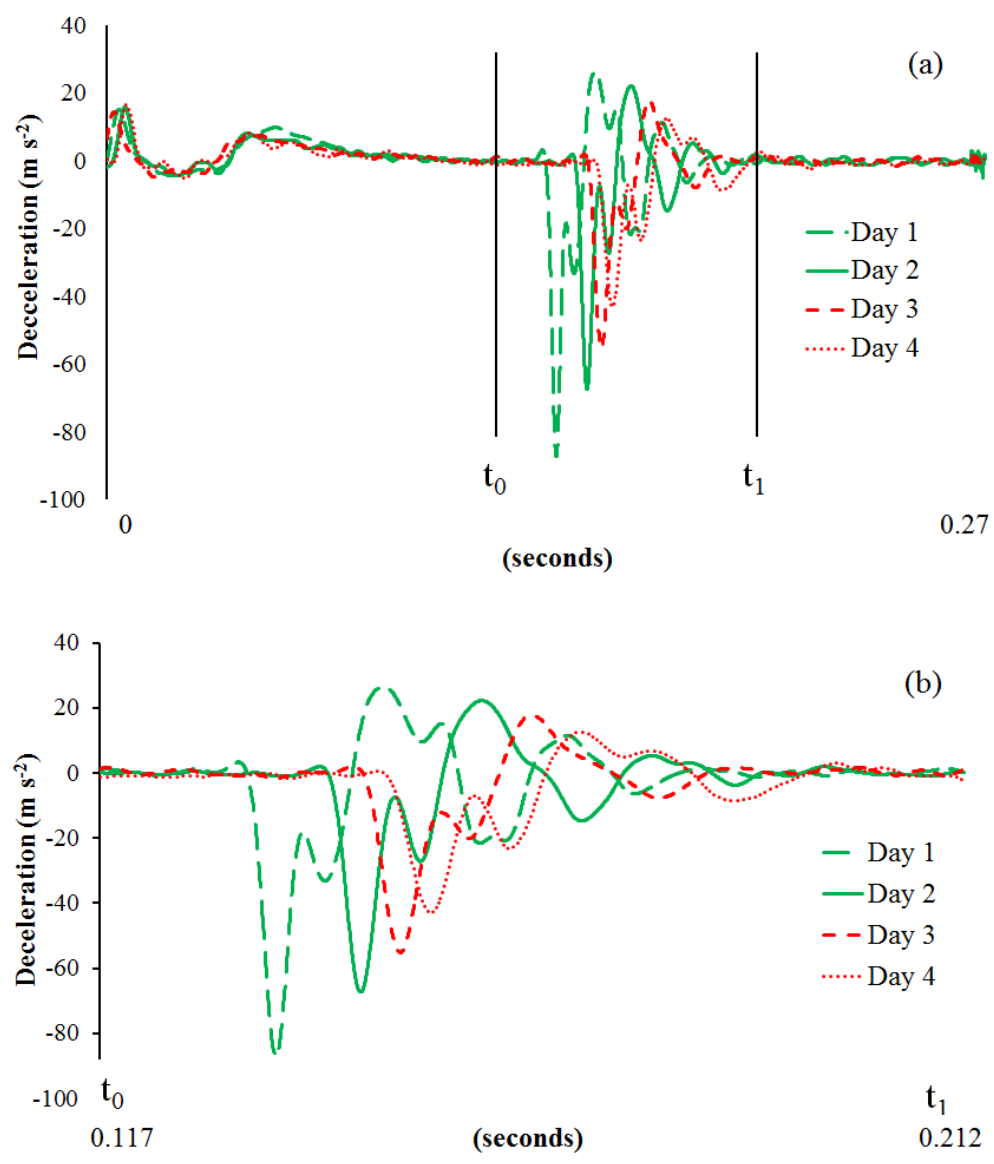

Figure3. An example of the method for processing deceleration signals. (a) Original collected signals for decelerations of one cherimoya in 4 different days and with different ripeness state, (b) cut signal between t0 and t1 that collects the impact of pad (A) against the cherimoya.

\subsection{Statistical analysis}

A partial least square (PLS) regression model was built for the prediction of destructive firmness according to the three non-destructive variables extracted from the prototype. Cross validation was carried out with an internal set using "leave out every 2nd". Root mean square error for cross validation (RMSECV) was obtained by comparing the predicted firmness with the experimental values. RMSECV was plotted against LVs to set the optimal number of LVs.

The model was tested to predict firmness with a random calibration set of 35 fruits. The root mean square error of the prediction and the $\mathrm{R}^{2}$ of the prediction were calculated. RMSEP was then expressed as RMSEP\% corresponding to the percentage of error of prediction calculated with RMSEP divided by the mean values of fruit firmness from the validation set.

\section{Results}

\subsection{Ripeness development}

141 Ripeness development during the four days was properly measured by the destructive variables: soluble solid content (Fig. 4) and destructive firmness (Fig. 5). 
Mean and LSD intervals (95.0\%)

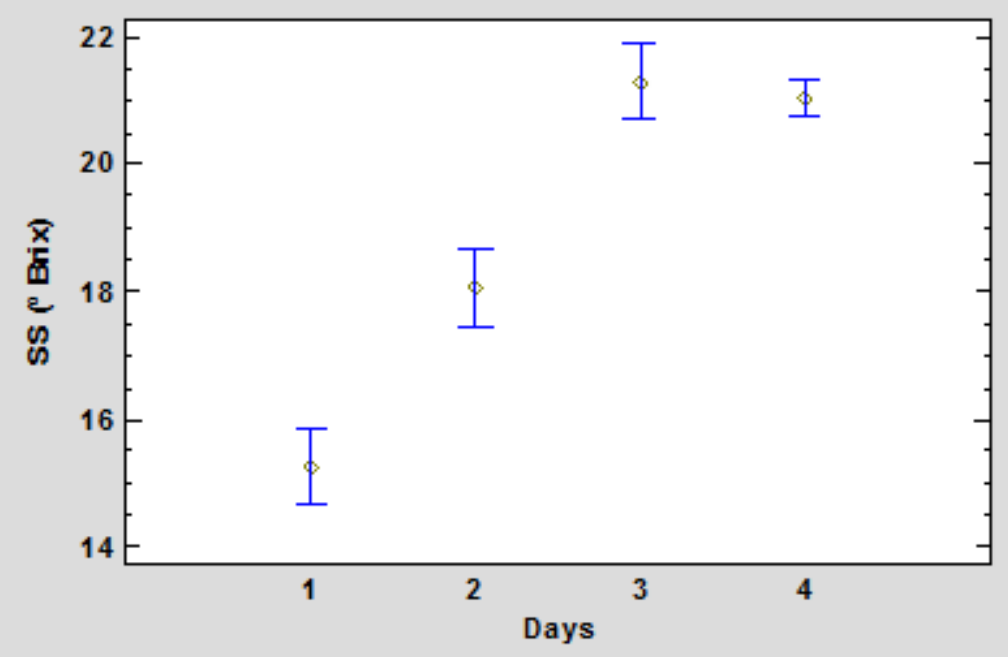

Figure 4. Soluble solid content development (mean and LSD intervals) during the four test days.

Mean and LSD intervals (95.0\%)

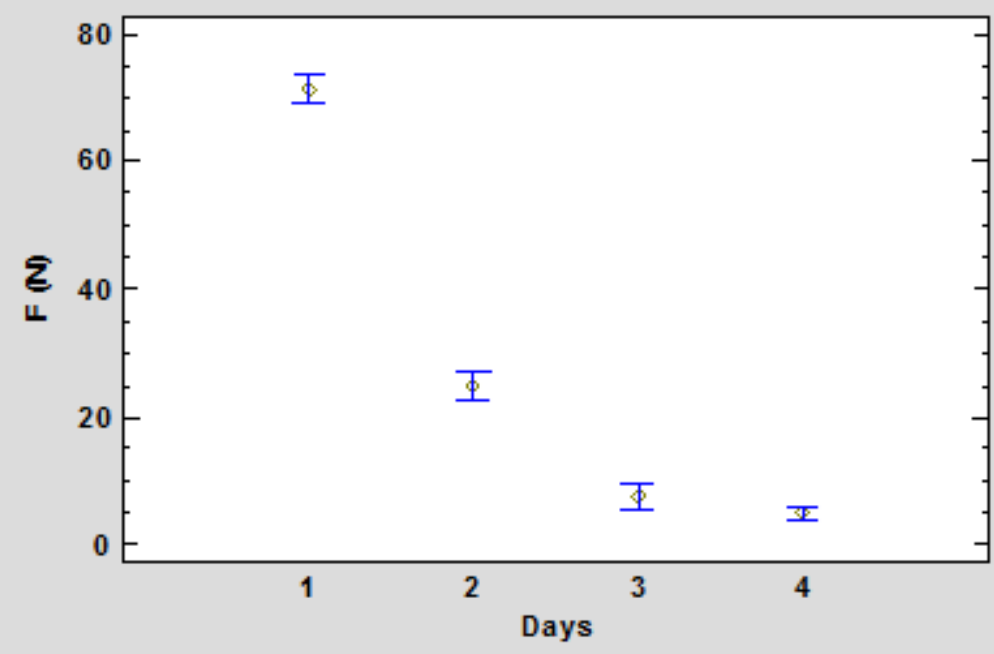

Figure 5. Destructive firmness (force, N) development (mean and LSD intervals) during the four test days.

Cherimoya fruit is characterised by a high perishability (3-6 d at $20^{\circ} \mathrm{C}$ ), Alique and Zamorano (2000). As registered before by Manriquez, Muñoz-Robredo, Gudenschwager, Robledo and Defilippi (2014) pulp firmness was very high at harvest. However, a rapid softening was observed coinciding with an increase in ethylene production and the increase in soluble solid content. The ready-to-eat stage was reached after 
3 or 4 days of storage at $20^{\circ} \mathrm{C}$. In the same way, the non-destructive variables extracted from the 153 prototype registered the ripening development parallel to the destructive firmness decrease (Figs. 6, 7 and 154 8). While soluble solid content was not significantly different from day 3 to day 4 (Fig. 4), the destructive 155 firmness was significantly higher from day 3 to day 4. In the same way, the non-destructive parameters extracted from the accelerometers curve were significantly higher from day 3 to day 4 .

Medias y $95,0 \%$ de Fisher LSD

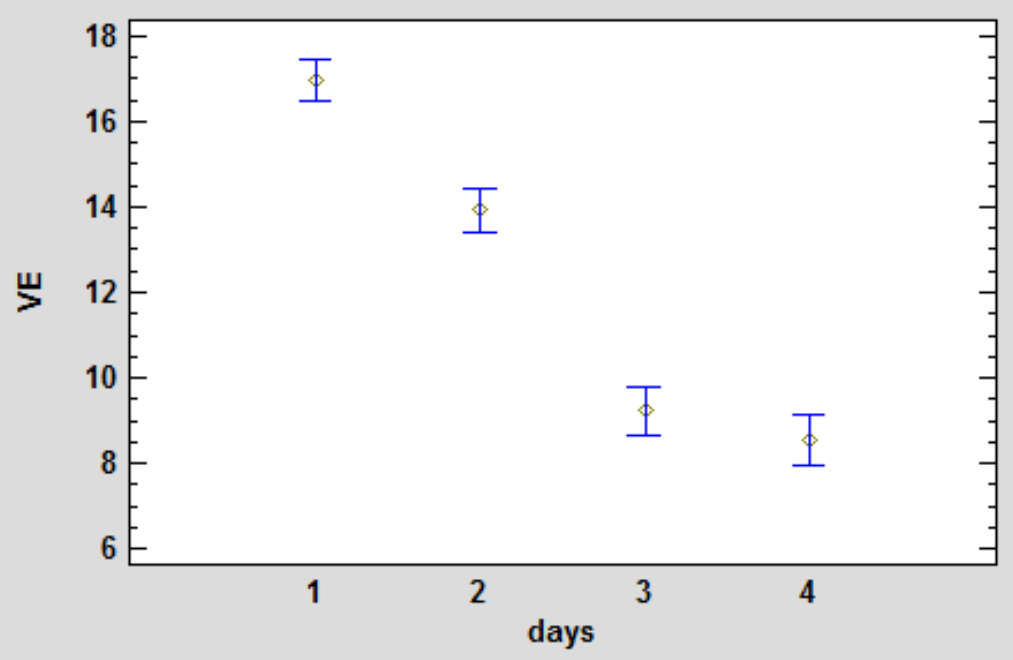

Figure 6. Non-destructive variable obtained from the prototype deceleration curve VE (mean and LSD intervals) during the four test days.

Medias y $95,0 \%$ de Fisher LSD

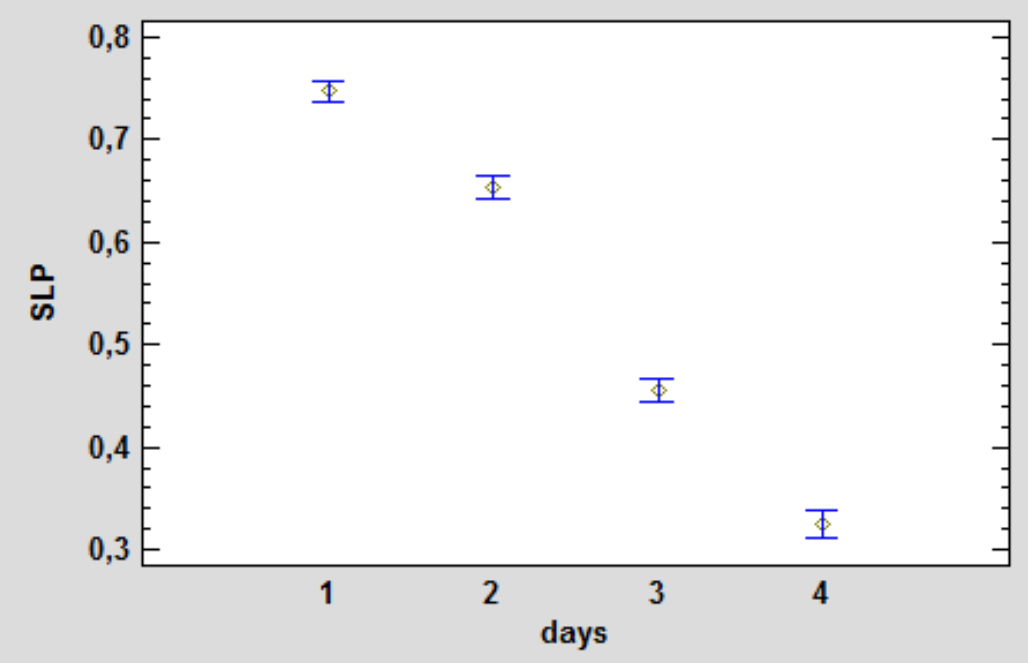




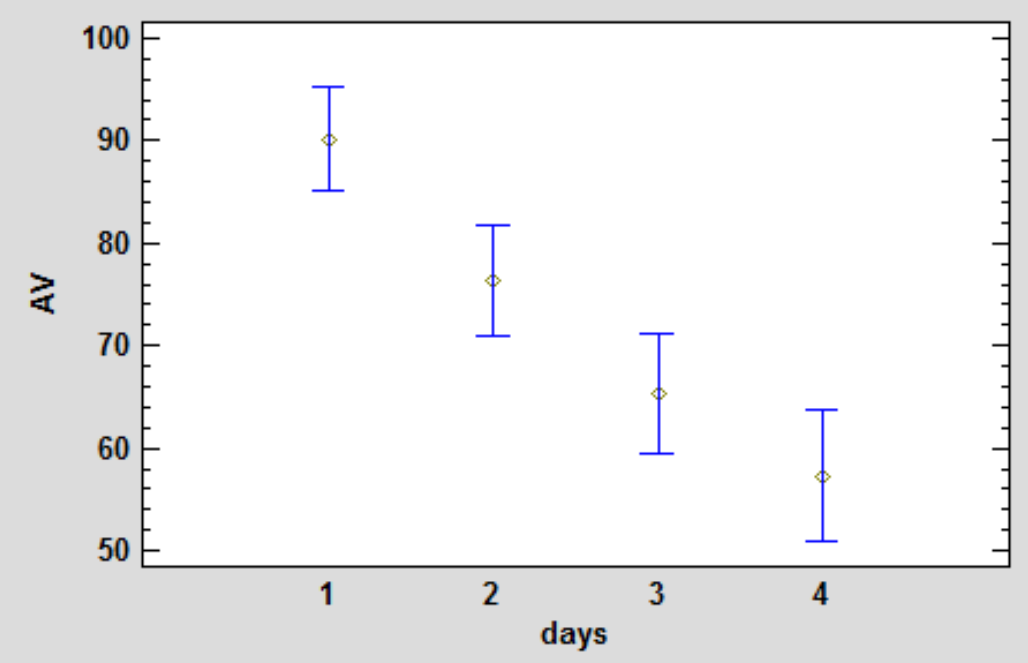

Figure 8. Non-destructive variable obtained from the prototype deceleration curve MAX (mean and LSD intervals) during the four test days.

\subsection{Fruit damage}

169

No damage was produced by the prototype impacting the fruit until the day 4 . On day 4 , some overripe cherimoyas were damaged.

171 3.3. Correlation between destructive firmness and non-destructive variables

172 On comparing the destructive firmness and the non-destructive variables extracted from the prototype

173 from the fourth day, they showed a clearly linear correlation, with a correlation coefficient of 0.91 ( $\mathrm{p}<$ $1740.05)$ to VE, $0.90(\mathrm{p}<0.05)$ to SLP and 0.90 ( $\mathrm{p}<0.05)$ to MAX (Figs. 9, 10 and 11 respectively). These 175 results are confirming that the studied non-destructive parameters extracted from the prototype are capable to monitor ripeness in a similar way to the destructive parameters. 
$F(N)=-0.7591+0.8365^{*} V E$

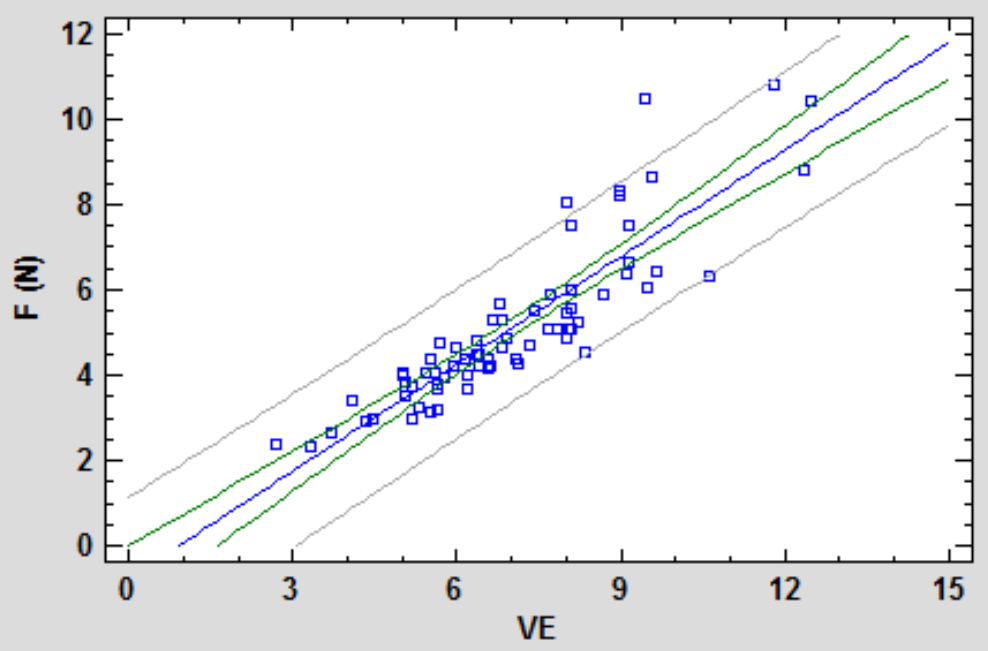

Figure 9. Linear relation between the destructive firmness (F, N) and the non-destructive firmness measured as VE

$F(N)=0.1047+15.3572^{*} S L P$

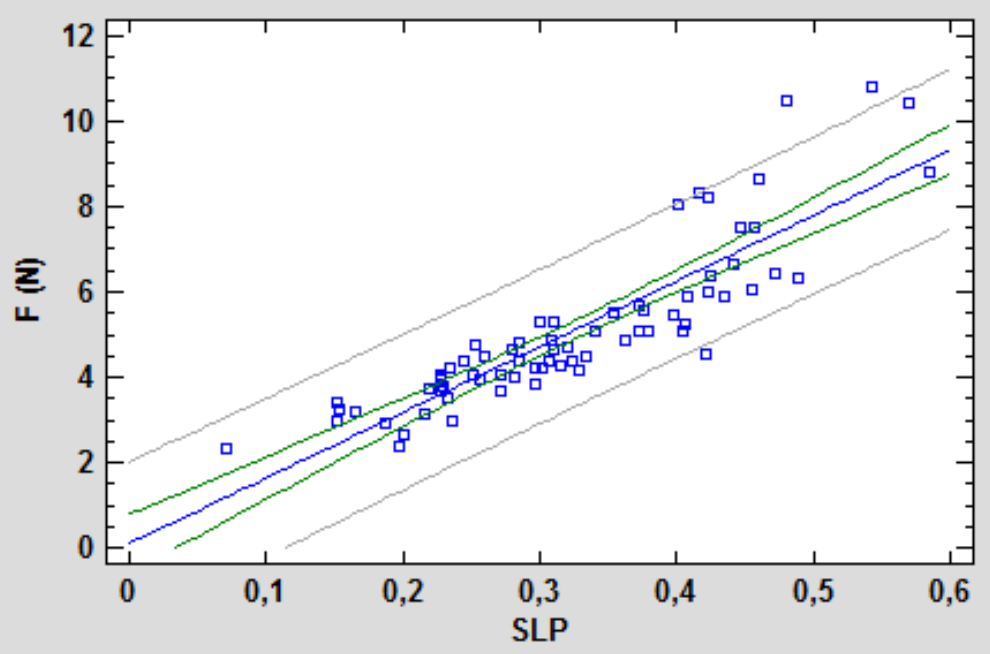

182 Figure 10. Linear relation between the destructive firmness (F, N) and the non-destructive firmness measured as SLP from the prototype, using the data tested on day 4. 


\section{$F(N)=-1.8380+0.1775^{*} \mathrm{MAX}$}

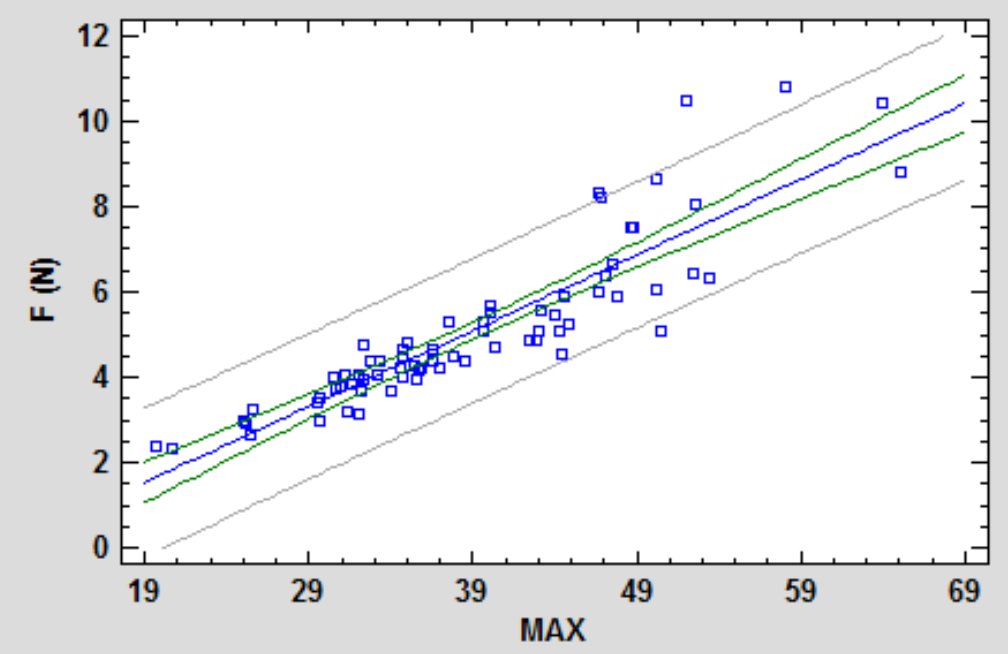

Figure 11. Linear relation between the destructive firmness (F, N) and the non-destructive firmness measured as MAX from the prototype, using the data tested on day 4.

3.4. Firmness prediction of the fourth day with the non-destructive data from third day

In order to predict firmness decay on day 4 (measured as destructive firmness, $\mathrm{F}(\mathrm{N})$ ) using the nondestructive measurements from day 3 (VE, SLP and MAX) and the fruit diameter, a partial least square model was developed. Table 1 shows the analysis of variance of the partial least square model explaining final firmness decay based on the non-destructive variables from day 3and the fruit diameter. The resulting model is a significant predictor for the destructive firmness based on non-destructive variables.

Cross validation was then carried out. Four components were used, with a $\mathrm{R}^{2}$ of 75.6 and a root mean square error for cross validation (RMSECV) of 0.99 .

Table 1. ANOVA analysis of the effect of the non-destructive variables from day 3 (SLP, MAX and VE) on the

\begin{tabular}{cccccc}
\multicolumn{6}{c}{ destructive firmness from day 4 $(\mathrm{F}(\mathrm{N}))$ from the PLS model. } \\
\hline Source & Sum of & df & Mean Square & F-value & P-value \\
& Square & & & & 0.0 \\
\hline Model & 191.745 & 4 & 47.9363 & 51.0038 & \\
Residues & 62.0306 & 66 & 0.939858 & & \\
\hline Total (corr.) & 253.776 & 70 & & & \\
\hline
\end{tabular}

A calibration set was used to test the prediction, with a $\mathrm{R}^{2}$ of 80.2, a root mean square of the prediction (RMSEP) of 0.0561 and a RMSEP percentage of 1.71 , Table 2. The high value of the $\mathrm{R}^{2}$ and the low values of the root mean square of the cross validation and the root mean square of the prediction indicated the goodness of the model. The number of components (Factor, LV - 4) that were needed to be extracted was selected according to the model comparison plot.

Table 2. Results of performance of firmness model for non-destructive firmness assessment of cherimoya fruits.

$$
\text { Factor }
$$




\begin{tabular}{ccccc}
\hline $\mathbf{( L V})$ & & & & \\
\hline 4 & 0.99 & 0.0561 & 1.71 & 80.2 \\
\hline
\end{tabular}

205

206

207

208

209

210

211

212

With the non-standardized coefficients from Table 3 the fitted equation can be built to predict the predicted values. According to the standardized coefficients the non-destructive variables building the model could be categorized according to their effect in the model, first the non-destructive variable related to the maximum value of the deceleration curve from day 3 (MAX3), second the non-destructive variable related to the slope of the deceleration curve from day 3 (SLP3), third the non-destructive variable related to the average deceleration value from day 3 (VE3) and fourth the diameter of the fruit.

Table 3. Coefficients from the PLS model from the variables of the fitted model (diameter and the non-destructive variables extracted from the prototype from day 3 ).

\begin{tabular}{ccc}
\hline \multicolumn{3}{c}{ Coefficients from the PLS model } \\
\hline & Standardised & Non-standardised \\
\hline Constant & 0 & $-16,73320$ \\
Diameter & $-0,10559$ & $-0,04969$ \\
MAX3 & 1,13693 & 0,43235 \\
SLP3 & $-0,50998$ & $-11,83370$ \\
VE3 & 0,21229 & 0,25411 \\
\hline
\end{tabular}

213

214 Figure 12 shows the measured values (destructive firmness on day 4) and the firmness predicted values 215 extracted from the PLS model using the non-destructive variables from the prototype on day 3 and the fruit diameter, with a 0.9 correlation coefficient $(\mathrm{p}<0.05)$.

Destrctuctive firmness (day 4) vs. Non-destructive firmness (day 3)

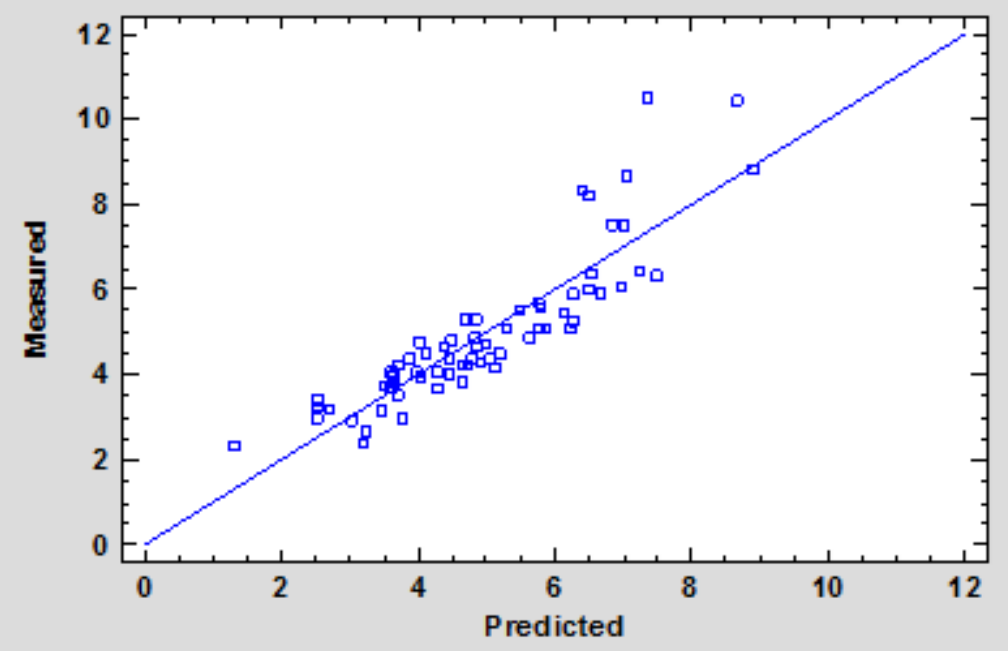

Figure 12. Measured values (destructive firmness on day 4) and firmness predicted values (from the PLS 
221 According to the model, destructive firmness from day 4 could be predicted based on the non-destructive parameters extracted from the prototype from day 3. However, it is necessary to incorporate the diameter values in the model. This parameter is necessary because the non-destructive impact measurements are affected by the size of the fruit. In any case, the firmness decay measured on day 4 could be predicted 24 $\mathrm{h}$ before using non-destructive measurements.

226 Cherimoya fruit ripens very fast, it softs and the peel darkens in the last ripeness stages. This final darkening and firmness decay could be predicted $24 \mathrm{~h}$ before it occurs when there are still not clear external effects.

\section{Discussion}

230

The cherimoya fruit has high perishability and is very susceptible to fruit damage. Fruit are harvested according to subjective criteria, when they change colour and have reduced touching resistance. The tender skin and the short shelf life, makes the fruit very susceptible to physical damage during handling, transport and marketing, restricting its commercialisation (Cordeiro \& Gouveia, 2013). Cherimoya fruit also ripens quickly, it softs and the peel darkens, being difficult to handle without producing damage (Franco-Mora et al., 2015). When the firmness decay and the darkening of the skin are clear it is already too late to detect firmness.

237 Dynamic hardness or stiffness measurement methods could offer useful tools in fruit ripening monitoring, 238 but they have limitations in applicability (Feljöldi et al., 2016). Traditional impact devices are not prepared to handle delicate fruit when is soft. The developed ultra-low pressure impact prototype has shown itself to be able to non-destructively assess firmness, even when the fruit is already soft, without damaging it.

In the traditional impact devices, a spherical head rod is used and the Hertz contact theory applied for the evaluation of the impact signal. This methodology is accurate when the fruit is also spherical. However, when measuring irregular shape fruits, as cherimoya, ensuring a uniform contact behaviour is difficult. The vacuum-jamming rod is capable of assuring a clean contact between the impact pad and the fruit, reducing the noise of the signal.

247 The ultra-low pressure pneumatic cylinder pad reduces fruit damage while measuring firmness of very 248 soft fruit and the jamming rod and cradle system are capable of adapting to the irregular shape of the fruit and increases accuracy when measuring irregular fruit. Final darkening and firmness decay could be predicted before it occurs. Based on this prototype a new easy to calibrate and use, non-expensive device could be developed and used on-line for postharvest sorting applications.

\section{Conclusions}

253 An impact prototype device with an ultra-low pressure pneumatic jamming rod has been developed. The

254 device is capable of adapting to the irregularities of the fruit shape and non-destructively assessing the decrease in cherimoya firmness during ripening without causing damage.

256 The measured destructive firmness and the non-destructive variables extracted from the prototype showed a clearly linear correlation, higher than 0.8 in all the cases. 

variables and diameter from day 3, with a $\mathrm{R}^{2}$ of 75.6 and a RMSECV of 0.9885 . A calibration set confirmed the prediction with a $\mathrm{R}^{2}$ of 80.2 and a RMSEP of 0.0561 .

261 Firmness decay and darkening (measured as destructive firmness) could be non-destructively predicted 24

$262 \mathrm{~h}$ in advance using the variables extracted from the prototype device signal. Based on this prototype, a

263 new, easy to calibrate and use, non-expensive device could be developed for use in on-line postharvest sorting applications.

\section{References}

Alique R.; \& Zamorano J.P. (2000). Influence of harvest date within the season and cold storage on cherimoya fruit ripening. Journal of Agricultural and Food Chemistry, 48, 4209-4216 http:// doi/abs/10.1021/jf9913561

Amend J.R.; Brown E.; Rodenberg N.; Jaeger H.M.; \& Lipson H. (2012). A Positive Pressure Universal Gripper Based on the Jamming of Granular Material. IEES Transactions of robotics, 28(2), 341-350 http:// doi: 10.1109/TRO.2011.2171093

Arendse, E.; Fawole, O.A.; Magwaza, L.S.; \& Opara, U.L (2018). Non-destructive prediction of internal and external quality attributes of fruit with thick rind: A review. Journal of Food Engineering, 217, 11-23 https://doi.org/10.1016/j.jfoodeng.2017.08.009

Blanes C.; Ortiz C.; Mellado M.; \& Beltrán P. (2015). Assessment of eggplant firmness with accelerometers on a pneumatic robot gripper. Computers and Electronics in Agriculture, 11, 44-50 https://doi.org/10.1016/j.compag.2015.01.013 Blanes, C.; Mellado, M.; \& Beltrán, P. (2016). Tactile sensing with accelerometers in prehensile gripper for robots. Mechatronics, 33, 1-12. http://hdl.handle.net/10251/81248. Chen, L.; Opara, U.L (2013). Texture meassurement approaches in fresh and processed foods- A review. Food Research International, 51, 823-835. https://doi.org/10.1016/j.foodres.2013.01.046

Cordeiro, N.; \& Gouveia, M. (2013). Changes in the mesocarp of Annona cherimola Mill. 'Madeira' during postharvest ripening. Postharvest Biology and Technology, 85, 179-184

Cortés, V.; Blanes, C.; Blasco, J.; Ortiz, C.; Aleixos, N.; Mellado, M.; Cubero, S.; \& Talens, P. (2017). Integration of simultaneous tactile sensing and visible and near-infrared reflectance spectroscopy in a robot gripper for mango quality assessment. Biosystems Enineering, 162: 112-123

290 https://doi.org/10.1016/j.biosystemseng.2017.08.005

De Oliveira, G.A.; Bureau, S.; \& Peira-Netto, A.B. (2014). Comparison of NIRS approach for prediction of internal quality traitsin three fruit species. Food Chemistry, 143, 223-230 https://doi.org/10.1016/j.foodchem.2013.07.122

Felföldi, J.; Kertész, I.; Nagy, D.; \& Zsom-Muha V. (2016). Non-Destructive impact method for quality assessment of horticultural products. Progress in Agricultural Engineering Sciences, 13(1)

296 https://doi/10.1556/446.13.2017.5

297 Franco-Mora, O.; Morales-Pérez, A.A.; Castañeda-Vildózola, A.; Morales-Rosales, E.J.; \& Sánchez-Pale, J.R. 298 (2015). Sprays Mixing Resveratrol and Benzylaminopurine Previous Harvest Helps to Preserve Postharvest Quality in Cherimoya. Journal of Agriculture and Life Science, 2(2), 16-24

300 García-Ramos F.; Valero C.; Hommer I.; Ortiz-Cañavate J.; \& Ruiz-Altisent M. (2005). Non-destructive fruit

302 http://dx.doi.org/10.5424/sjar/2005031-125

303 Ibertest. Available online: www.ibertestint.com (accessed on 20 June 2018). 
Khalifa, S.; Komarizadeh, M.H.; \& Tousi, B. (2011). Usage of fruit response to both force and forced vibration applied to assess fruit firmness- a review. Australian Journal of Crop Science, 5(5): 516-522

https://search.informit.com.au/documentSummary;dn=280197917204698;res=IELHSS

Lorente, D.; Aleixos, N.; Gómez-Sanchis, J.; Cubero, S.; García-Navarrete, O.L.; \& Blasco, J. (2012). Recent advances and applications of hyperespectral imaging for fruit and vegetable quality assessment. Food and Bioprocess Technology, 5, 1121-1142

\section{https:// doi:10.1007/s11947-011-0725-1}

Manriquez D.A.; Muñoz-Robredo P.; Gudenschwager O.; Robledo P.; \& Defilippi F.G. (2014). Development of flavor-related metabolites in cherimoya (Annona cherimola Mill.) fruit and their relationship with ripening physiology. Postharvest Biology and Technology, 94, 58-65

https://doi.org/10.1016/j.postharvbio.2014.03.004

Mizarch, A.; Nahir, D.; \& Ronen, B. (1992). Mechanical Thumb Sensor for Fruit and Vegetable Sorting. Transactions of ASAE, 35(1), 247-250

https//doi.org/10.13031/2013.28595

Nicoaï, B.; Beullens, K.; Bobelyn, E.; Peirs, A.; Saeys, W.; Theron, K.I.; \& Lammertyn, J. (2007). Nondestructive measurement of fruit and vegetable quality by means of NIR spectroscopy: A review. Postharvest Biology and Technology, 46(2), 99-118

https://doi.org/10.1016/j.postharvbio.2007.06.024

Opara, U.L.; \& Pathare, P.B. (2014). Bruise damage measurement and analysis of fresh horticultural product: a review. Postharvest Biology and Technology, 91, 9-24

https://doi.org/10.1016/j.postharvbio.2013.12.009

Ruiz-Altisent M.; Ruiz-Garcia L.; Moreda G.P.; Lu R.; Hernandez-Sanchez N.; Correa E.C.; Diezma B.; Nicolai B.; \& García-Ramos J. (2010). Sensors for product characterization and quality of specialty crops". A review. Computers and Electronics in Agriculture, 74(2), 176-194

https://doi.org/10.1016/j.compag.2010.07.002

Valero C.; Crisosto C.H.; \& Slaughter D. (2007). Relationship between nondestructive firmness measurements and commercially important ripening fruit stages for peaches, nectarines and plums. Postharvest Biology and Technology, 44 (3), 248-253

https://doi.org/10.1016/j.postharvbio.2006.12.014

Wang, H.; Peng, J.; Xie, C.; Bao, Y.; \& He, Y. (2015). Fruit quality evaluation using spectroscopy technology: a review. Sensors, 15(5), 11889-11927

https:// doi:10.3390/s150511889 